\title{
Quantidade e qualidade na pesquisa em educação, na perspectiva da dialética marxista!
}

Alceu Ravanello Ferraro*

Resumo: Este trabalho trata da relação entre métodos quantitativos e qualitativos nas ciências sociais em geral e na área da educação em particular. Começa focalizando a orientação positivista da Sociologia, assim como de outras ciências sociais em sua origem, mas rejeitando a identificação sumária entre métodos quantitativos e positivismo. Aborda, então, a querela metodológica, com destaque para três teses a respeito da relação entre métodos quantitativos e qualitativos: a da oposição ou incompatibilidade; a da complementaridade; e a da unidade. Esta última, como unidade na perspectiva da dialética marxista. Por fim, sugere que, em vez de nos inquirirmos sobre qual a competência metodológica de maior valor em absoluto, deveríamos perguntar-nos se e como diferentes competências metodológicas poderáo articular-se no estudo de um determinado objeto ou problema social ou educacional.

Palavras-chave: quantidade; qualidade; metodologia de pesquisa; educação; dialética marxista.

\section{Quantity and quality in research on education from the perspective of Marxist dialectics}

Abstract: This paper deals with the relationship between quantitative and qualitative methods in the social sciences in general and in the area of education in particular. It starts by focusing on the positivistic orientation that sociology and other social sciences had in their origin, but rejects a simple identification of quantitative methods and positivism. It then discusses the methodological dispute, highlighting three theses on the relationship between quantitative and qualitative methods: the thesis of opposition or incompatibility, the thesis of complementariness and the thesis of unity. The latter is seen as a unity in the perspective of Marxist dialectics. The paper finally suggests that instead of wondering what is the methodological competence that has the highest absolute value, we should ask whether and in which way different methodological competences can be brought together in the study of a particular object or social or educational problem.

Key words: quantity; quality; research methodology; education; Marxist dialetics.

\footnotetext{
Professor do Programa de Pós-Graduação em Educação da Universidade Federal do Rio Grande do Sul, Brasil. aferraro@adufrgs.ufrgs.br

I. Trabalho desenvolvido com apoio do CNPq.
} 
A distinção entre métodos quantitativos e métodos qualitativos e a disputa entre os adeptos de uns e de outros, tanto nas ciências sociais como na área da educação, têm uma história. Penso que lembrar alguns aspectos dessa história pode ajudar a compreender melhor não só os passos nesse percurso, como também os impasses e os desafios que se colocam hoje, no campo metodológico, à pesquisa social, em geral, e à pesquisa educacional, em particular.

Em sua emergência e desenvolvimento, as ciências exatas ou duras contaram com o suporte fundamental da Matemática. Por sua vez, as ciências sociais, como a Sociologia e a Ciência Política, e as ciências sociais aplicadas, como a Economia e a Demografia, tiveram, em sua origem e desenvolvimento, como referência e modelo, as ciências exatas; e, como suporte, a Matemática. Trago o exemplo da Sociologia.

\section{A origem positivista da Sociologia}

A emergência da Sociologia como ciência da sociedade tem relaçáo estreita com o positivismo. Segundo Michael Löwy, o positivismo assenta-se sobre três ideias básicas: 1) que a sociedade humana é regulada por leis naturais; 2) que os métodos e os procedimentos utilizados para conhecer a sociedade náo diferem em nada daqueles empregados para conhecer a natureza; e 3) que, como conclusão, as ciências sociais devem funcionar exatamente segundo o modelo de objetividade, neutralidade e isenção de juízos de valor das ciências da natureza (Löwy, 1985, p. 35-36).

Filho legítimo da filosofia das luzes, do enciclopedismo do século XVIII, o positivismo também teve, segundo o autor, num primeiro momento, um caráter utópico enquanto "uma visão do mundo de dimensão utópica, crítica e, até certo ponto, revolucionária” (ibidem, p. 37-38). O Marquês de Condorcet foi o primeiro a formulá-lo de maneira mais precisa nessa sua versão utópica, iluminista, revolucionária, embora tenha sido seu discípulo, Saint-Simon, o primeiro a aplicar o termo "positivo" à ciência (ciência positiva).

Seria incorrer em anacronismo atribuir a Condorcet a paternidade da Sociologia. No entanto, em sua obra Esboço de um quadro histórico dos progressos do espirito humano, de 1793, ele intuiu com clareza a possibilidade de uma ciência da sociedade à semelhança das ciências da natureza. Apesar das circunstâncias trágicas, o autor revela um otimismo histórico surpreendente:

Se o homem pode predizer com uma segurança quase integral os fenômenos dos quais conhece as leis; se, mesmo quando estas lhe são desconhecidas, ele pode, a partir da experiência do passado, prever com uma grande probabilidade os acontecimentos do futuro; por que ver-se-ia como um 
empreendimento quimérico aquele de traçar, com alguma verossimilhança, o quadro dos destinos futuros da espécie humana, a partir dos resultados de sua história? (Condorcet, 1993, p.176).

Condorcet vê grandes perspectivas na aplicação do cálculo na produção do conhecimento científico, estendendo tal aplicação também à produção dos conhecimentos que devem "servir de base para a arte social" (ibidem, p. 192). Sua aposta na Matemática era tal, que, em seu projeto de instrução pública, queria sempre dois professores, um dos quais "particularmente encarregado das aplicaçóes das matemáticas às ciências morais e políticas" (Condorcet apud Grawitz, 1996, p. 329).

Löwy descreve com muita propriedade a guinada representada pelo positivismo conservador de Augusto Comte, em que o próprio termo positivo muda de significado:

[...] para o positivismo em sua fase utópica, o termo preconceito serve a uma funçáo revolucionária e crítica - é sempre o preconceito das classes dominantes, preconceito clerical, absolutista, obscurantista, fanático, intolerante, dogmático; com Comte, esse sentido muda: é o preconceito revolucionário de Condorcet, que apoiou a Revolução Francesa, ou revolucionário socialista de Sant-Simon. (Löwy, 1985, p. 39).

Aquelas características fundamentais do positivismo lembradas acima, que estiveram presentes na formulação de Condorcet, mantiveram-se na reorientação imprimida por Comte, apenas com sinal trocado: de uma orientação utópicorevolucionária, voltada para o progresso, na primeira formulação, o positivismo passou a uma orientação conservadora, preocupada com a ordem, na segunda. Em ambos os casos, um lugar de destaque para a Matemática e sua aplicação na produção do conhecimento. Daí, a desenvolver-se uma fé incondicional, acrítica, nas estatísticas, inclusive nas estatísticas da educação, não iria mais que um passo, mesmo tendo a história demonstrado amplamente que a disponibilidade crescente de estatísticas nunca foi suficiente para melhorar a educação.

No entanto, penso que se estaria incidindo em dois grandes equívocos se daí se deduzisse: primeiro, que todo recurso à Matemática, à Estatística, ou aos ditos métodos quantitativos seja positivismo; segundo, que o recurso aos métodos qualitativos esteja imune ao positivismo. Esse duplo equívoco parece estar presente na obra de Lessard-Hébert, Goyette e Boutin (1994, p. 31), pelo fato mesmo de falarem em "paradigmas positivista e interpretativo", ficando subentendido, de um lado, que toda quantificação na pesquisa seria positivismo e, de outro, que a pesquisa dita qualitativa estaria a salvo do positivismo. 
No Brasil, a propósito dessa identificação entre metodologias quantitativas e positivismo, Marli Elisa D. A. André, mesmo ocupando-se de metodologias qualitativas, não deixou de dedicar alguns parágrafos de grande interesse às metodologias quantitativas. Sob o título "Para além da dicotomia qualitativo-quantitativo", a autora faz um alerta e oferece uma orientação que vale reproduzir aqui. $\mathrm{O}$ alerta: "O uso do termo 'pesquisa quantitativa' para identificar uma pesquisa positivista de ciência parece-me no mínimo reducionista. Associar quantificação com positivismo é perder de vista que quantidade e qualidade estão intimamente relacionadas." (André, 2002, p. 24). E a orientação, que considero de suma importância:

Por essa razão não me parece ser muito conveniente continuar usando o termo 'pesquisa qualitativa' de forma táo ampla e genérica como preferem alguns [...]. Eu reservaria os termos quantitativo e qualitativo para diferenciar técnicas de coleta ou, até melhor, para designar o tipo de dado obtido, e utilizaria denominaçóes mais precisas para determinar o tipo de pesquisa realizada: histórica, descritiva, participante, fenomenológica etc. (Ibidem, p. 24, grifos meus).

Segundo a autora, se, num determinado momento, foi até interessante o emprego do termo "qualitativo" para identificar uma perspectiva de conhecimento que, a partir do final do século XIX, se opunha ao positivismo, haveria agora necessidade de ir além, de ultrapassar a dicotomia qualitativo-quantitativo (André, 2002, p. 25).

Resumindo, entendo que a concepção positivista pode estar subjacente a qualquer método e técnica de pesquisa. Nesse sentido, não é o quantitativo em si que constitui o positivismo, embora o positivismo tenda a sobrevalorizar o quantitativo. Durkheim (1971, p. 24) não está se referindo apenas ao uso das estatísticas, quando afirma e prescreve que "os fenômenos sociais são coisas e devem ser tratados como coisas", por constituírem "o único datum oferecido aos sociólogos" como ponto de partida da ciência (ibidem, p. 38). Nessa perspectiva, podem ser tratadas como coisas tanto uma estatística como, por exemplo, qualquer informação obtida por meio de uma entrevista ou da observação.

Nas minhas contas, foi a partir da década de 1980 que se assistiu, pelo menos no Brasil, na área específica da pesquisa em educação, a um crescente desencanto e progressivo abandono de tudo o que pudesse caber sob o nome de métodos quantitativos, mesmo envolvendo estatísticas elementares como percentagens. Se isso, de um lado, permitiu um grande desenvolvimento das metodologias qualitativas e o reconhecimento da legitimidade destas, de outro lado, ajudou a legitimar a retirada da Estatística dos currículos dos cursos de Pedagogia, bem como dos cursos de Pós-Graduação em Educação. 


\section{Matemáticas e estatísticas}

A querela entre quantidade e qualidade leva-nos à questáo das matemáticas e das estatísticas.

Desafiando concepções correntes nesse campo, a já citada M. Grawitz² (1996, p. 329) vem dizer que as matemáticas são, antes de tudo, uma linguagem, um meio de comunicação; que nos dias atuais ganha relevo a distinção entre matemáticas qualitativas e quantitativas; que as matemáticas qualitativas compreendem as não numéricas e as ordinais, ao passo que as quantitativas compreendem as ordinais e as cardinais. E segue dizendo que as matemáticas não são mais que um meio a serviço de hipóteses que pretendem dar conta da realidade ou explicá-la. De tudo isso, segundo a autora, emerge o problema de como, sem empobrecê-los, ordenar ou tornar quantificáveis os elementos qualitativos mais interessantes, processo este que exige duas transformaçóes: de um lado, a evolução do próprio instrumento matemático e, de outro, a transformação dos dados qualitativos ${ }^{3}$.

$\mathrm{Na}$ obra A ilusão das estatísticas (Besson, 1995a), Besson, no texto "As estatísticas: verdadeiras ou falsas?" (Besson, 1995b, p. 43) diz que a velha polêmica do quantitativo e do qualitativo, que opóe entre si os adeptos da medida e os seus difamadores, assemelha-se àquela que, a partir do século VIII, opunha entre si iconoclastas e iconólatras: aqueles, entendendo que significante e significado eram da mesma natureza; estes, interditando o sagrado e suas margens de qualquer representação.

Aos “'qualitativistas' que protestam contra a redução do ser ao quantum, do como ao quanto", Besson responde em termos que podem projetar luz sobre o tema aqui abordado. "Mas a contagem - diz ele - pressupóe uma definição operatória e o quanto pressupóe um como: o estatístico não se limita a contar; ele define (ou retoma definiçôes impostas); ele classifica segundo essas definiçôes e, in fine, conta o que classificou." E acrescenta: "Todo quadro de cifras tem assim uma dupla natureza: qualitativa e quantitativa. Sua estrutura, os títulos das linhas e das colunas traduzem a modelização preliminar do fenômeno." (Ibidem, p. 4647 , grifos do autor).

Em outro texto da mesma obra, o autor pergunta: "Será preciso, depois de termos acreditado que as estatísticas medem a realidade e depois de termos visto que elas só a observam, condenar as estatísticas?". Pergunta que ele mesmo responde, dizendo que elas não merecem nem o excesso de honra que se lhes rende, nem a indignidade que se lhes quer imputar (Besson, 1995c, p. 257, grifos do autor).

Maurice Comte também nos dá uma dica sumamente interessante em relação

2. São minhas as traduções do francês (Grawitz e Wetter) e do italiano (Delli Zotti).

3. Sobre a questão, cf. Grawitz (1996, p. 329-34I). 
a como encarar as estatísticas. Segundo ele, "as estatísticas não são somente uma informação, um meio de análise”; ao contrário, é necessário que elas sejam tomadas também "como objeto de análise", isto é, é necessário que se passe por trás do espelho das cifras, de sorte a que se lhes possa restituir o sentido (Comte, 1995, p.110, grifos no original). Assim, o velho adágio: Dados são dados deveria dar lugar a este outro: Dados são objeto de análise, não importando se tidos como de natureza quantitativa ou qualitativa.

Bernardete A. Gatti fez uma revisão atenta de trabalhos científicos produzidos nas últimas três décadas no Brasil, na área da educação, que utilizaram abordagens quantitativas. Reporto-me aqui a duas observaçóes da autora que suscitam preocupação. Vem, em primeiro lugar, a constatação de que, atualmente, na pesquisa educacional, poucos estudos empregam metodologias quantitativas. E o que é mais grave: "Há mais de duas décadas que na formação de educadores e de mestres e doutores em educação não se contemplam estudos disciplinares sobre esses métodos" (Gatti, 2004, p. 13). A segunda observaçâo refere-se à falta de tradição na área: "O uso de dados quantitativos na pesquisa educacional no Brasil nunca teve, pois, uma tradição sólida, ou uma utilização mais ampla." (Ibidem, p. 14).

Contribui muito para o entendimento das observaçóes de B. A. Gatti a avaliaçáo que faz Natália de Lacerda Gil (2007) a respeito do lugar da estatística na pesquisa educacional. "No Brasil - diz ela -, a perspectiva de estudo da história da educação em que as estatísticas são tomadas como fonte privilegiada não teve grande repercussão e, menos ainda, o estudo crítico dessas fontes.” (Gil, 2007, p. 51). Na sequência, ao referir as três razóes que, segundo um grupo de pesquisadores $^{4}$, explicariam tal desinteresse, a autora acrescenta uma quarta razão relacionada com a formação dos pesquisadores de História da Educação no Brasil, os quais consideram "difíceis e entediantes" as ciências exatas. Para ela, aqueles que se especializaram na área educacional mantêm uma relação quase sempre "de tédio e medo" em relação à estatística.

\section{Gênese da querela metodológica}

A questão aqui não é saber quando surgiram e como se desenvolveram os métodos quantitativos e qualitativos nas ciências sociais e na educação, mas apenas

4. A autora sintetiza as três razões que, na avaliação de Faria Filho, Neves e Caldeira (2005), estariam na origem do desinteresse, no País, por estudos dessa natureza: "Em primeiro lugar estaria o próprio percurso da historiografia da educação brasileira, cujas pesquisas, pela sua forte filiação filosófica, dispensam informações estatísticas. Em seguida os autores mencionam o afastamento desses pesquisadores com relação à história quantitativa. Por fim, consideram que as opções de pesquisa prevalecentes na área, pela escolha que fazem dos objetos e fontes, não têm trazido a necessidade de reflexão mais aprofundada sobre a estatística escolar." (Gil, 2007, p. 5I). 
tecer algumas consideraçóes sobre a emergência da querela que se estabeleceu entre adeptos de uns e outros métodos.

Já vão mais de quarenta anos desde a publicação de Social Research: Strategies and Tactics, de Bernard S. Phillips (1966), com tradução publicada no Brasil em 1974 (Pesquisa social: estratégias e táticas). Nessa obra, ao mesmo tempo que sintetizava a controvérsia então reinante entre adeptos da pesquisa quantitativa e adeptos da pesquisa qualitativa no campo das ciências do comportamento e sinalizava o momento histórico da emergência dessa controvérsia, o autor jogava esperança, e também água fria, na direção de ambas as correntes. Dizia ele textualmente:

$\mathrm{Na}$ maioria das ciências do comportamento, parece existir um ajuste incômodo entre os que consideram a pesquisa algo altamente estruturado, objetivo, quantitativo e rigoroso e os que possuem uma orientação mais qualitativa e estáo menos preocupados com uma prova rigorosa. Os defensores de ambos os métodos reivindicam superioridade, mas tanto de um como de outro podem provir resultados triviais e proveitosos. (Phillips, 1974, p. 129)

Ainda segundo Phillips (1974, p. 130), a obra de S. J. Thomas e F. Znaniecki, The Polish Peasant in Europe and America (Os camponeses polacos na Europa e na América), publicada nos Estados Unidos em 1918/20, teria sido o principal deflagrador da controvérsia que se seguiu entre métodos qualitativos e quantitativos. A razão apontada é a seguinte: nessa obra, Thomas e Znaniecki haviam feito "bastante uso de documentos pessoais, tais como cartas e autobiografias, a fim de apresentar uma série de 'histórias de vida' detalhadas ou estudos de casos específicos". Metodologia que, mais tarde, seria batizada de qualitativa. Enquanto vários sociólogos passavam a ver nesse método uma excelente oportunidade de obter uma avaliaçáo completa de todas as fases da vida e, especialmente, da vida interior da pessoa, para diversos outros sociólogos, o novo método era por demais subjetivo, permitindo ao pesquisador selecionar histórias de vida que satisfizessem seus próprios objetivos (Phillips, 1974, p. 130).

Mais recentemente, M. Grawitz sustentou o mesmo ponto de vista, a saber, que o conflito entre métodos quantitativos e métodos qualitativos teria sua origem na já referida obra de Thomas e Znaniecki, os quais, diz ela, "concebiam seu estudo como uma pesquisa científica, levando em conta ao mesmo tempo fatores objetivos e comportamentos subjetivos que influenciavam a vida social" (Grawitz, 1996, p. 321). E esclarece:

Eles queriam, através destes últimos, verificar suas hipóteses, construir generalizaçôes aplicáveis a outras situaçôes sociais. 
Eles desejavam antes de tudo fazer reconhecer o valor metodológico dos documentos pessoais (cartas, biografias) que eles utilizavam e consideram como "o tipo perfeito de material sociológico”. (Grawitz, 1996, p. 321).

Ainda segundo a autora, a repercussão que essa querela metodológica haveria de ter se deveria ao fato de que ela "levantava todo o problema da generalização a partir de casos particulares, colocando em questão a técnica, táo praticada nos Estados Unidos, dos estudos de caso" (Grawitz, 1996, p. 321, grifo da autora).

Em relação à questão de que me venho ocupando, penso que a obra de Thomas e Znaniecki constitui, sim, um marco importante, principalmente se se pensa na Sociologia norte-americana. Mas há quem ache que se deva retroceder mais no tempo. Marli E. D. A. de André (2002, p. 25), por exemplo, apoiando-se em estudo de Smith e Heshusius (1984), situa o início desse debate no final do século XIX. De minha parte, penso que a questão da relação entre quantidade e qualidade vem de mais longe ainda, remontando pelo menos a Hegel (princípios do século XIX) e a Marx e Engels (terceiro quartel do século XIX), como se verá adiante.

Em 1966, quando da publicação de seu livro, o já citado Phillips (1974, p. 130) avaliava que essa controvérsia já estava até certo ponto solucionada, concordando a maioria dos sociólogos que "tanto os estudos de casos específicos como as estatísticas podem contribuir para o processo científico". Mais recentemente, Grawitz (1996, p. 322) chegou a falar em "reconciliação do qualitativo do ideográfico e do quantitativo [do nomotético]".

No prefácio ao seu livro A pesquisa de terreno, cujo original inglês data de 1984, Robert G. Burgess (1997, p. IX) observa que, se, de um lado, a investigação sociológica foi, em dada altura, estritamente identificada com os métodos de inquérito, de outro, a investigação antropológica se baseava em estudos intensivos, usando métodos de trabalho de campo incluindo a observaçáo participante. Segundo o autor, essa táo marcada dicotomia entre a prática e os procedimentos de pesquisa nessas duas disciplinas já não existia no início dos anos 1980 , porquanto os sociólogos estavam recorrendo à pesquisa de campo e os antropólogos, empenhando-se na realização de inquéritos.

No que se relaciona com a relação entre métodos qualitativos e quantitativos, sigo aqui a classificação proposta por Gamboa (2007, p. 34-53), para quem as concepçóes básicas a respeito se reduzem a três: a daqueles(as) que veem incompatibilidade, oposição ou dicotomia entre quantidade e qualidade; a daqueles(as) que veem complementaridade entre quantidade e qualidade; e a daqueles(as) que veem unidade entre quantidade e qualidade, pensando essa unidade em termos seja de integração, seja de um continuum, seja de uma unidade dialética. 


\section{A tese da falsa dicotomia entre quantidade e qualidade}

A obra de Goode e Hatt (original de 1952) é aqui lembrada por dois motivos: primeiro, por ser o que se poderia definir como um manual de pesquisa social de corte positivista; segundo, por ter sido talvez a primeira obra a se contrapor com clareza e firmeza à tese da dicotomia entre quantidade e qualidade.

No que se refere ao primeiro ponto, quase ao final do livro, ao tratarem de "Alguns problemas na análise qualitativa e na análise do caso", os autores fazem questão de declarar que a principal linha de pensamento que mantiveram em toda a obra foi "a de que a sociologia tem os mesmos fundamentos das demais ciências" (Goode; Hatt, 1969, p. 398). Ora, tal afirmação sintetiza com precisão um dos elementos definidores do positivismo elencados por Löwy (1985, p. 3536; 1988, p. 17).

No entanto, o que aqui mais interessa diz respeito ao segundo ponto acima levantado e está justamente no fato de os referidos autores se posicionarem claramente contra a tese da dicotomia ou incompatibilidade entre estudos quantitativos e estudos qualitativos, no que se afastam do positivismo, o qual sustenta a unidade metodológica na construção do conhecimento em todas as ciências. Para os autores referidos, "[...] a pesquisa moderna deve rejeitar como uma falsa dicotomia a separação entre estudos 'qualitativos' e 'quantitativos', ou entre pontos de vista 'estatístico' e 'não estatístico'”. O mais interessante é o argumento utilizado pelos autores para sustentar esta posição: "A aplicação da matemática à sociologia não garante rigor da prova mais do que o uso de insight garante a significância da pesquisa." (Goode; Hatt, 1969, p. 398, grifos no original).

Para Goode e Hatt, não importa quão precisas sejam as medidas, uma vez que "o que é medido continua sendo uma qualidade", de sorte que "num sentido fundamental a pesquisa pode ser chamada de qualitativa". Ainda, segundo os autores, se, de um lado, o que se mede na pesquisa é uma qualidade, de outro, a pesquisa social mais qualitativa "tenta medidas aproximadas". Assim, por exemplo, quando os historiadores "falam de 'um crescente sentimento antimonarquista durante o reinado de Luís XVI'” ou, ainda, quando o sociólogo "comenta que o indivíduo bem integrado dentro de um grupo muito coeso é mais capaz de suportar choques emocionais do que outros indivíduos." Em ambos os exemplos, dizem os autores, "supóem-se medidas de importantes qualidades", estejamos ou não satisfeitos com o seu grau de precisão (ibidem, p. 399, grifos no original).

Em síntese, a tese dos autores citados é que não há dicotomia ou oposição entre qualidade e quantidade na pesquisa social. E note-se que essa tese foi sustentada há mais de meio século e que o foi justamente por dois autores que podem ser considerados de fé positivista. 
Surpreende, por isso, que, decorrido tanto tempo desde o lançamento do livro de Goode e Hatt (1952), se continue sustentando a existência de dicotomia, oposição ou descontinuidade entre quantidade e qualidade. Ou entáo que, como em Erickson (apud Lessard-Hébet; Goyette; Boutin, 1994, p. 31-33, grifos meus), se proceda como se assim fosse, contrapondo a "investigação interpretativa" àquilo que se chama de "abordagem positivista/behaviorista", de sorte a que não se possa esperar mais do que uma coexistência entre os dois paradigmas - o novo e o velho.

Esta discussão sugere duas questốes que merecem atenção. A primeira pode ser posta assim: estaria, porventura, incorrendo em positivismo quem tentasse, hoje, retomar o ponto de vista de Goode e Hatt, de que não há oposição entre quantidade e qualidade? Penso que não. Ademais, a identificação das metodologias quantitativas com positivismo e behaviorismo contribui mais para confundir do que para esclarecer a relação entre quantidade e qualidade. E a segunda questão: Se não é de oposição, como definir, então, a relação entre quantidade e qualidade?

\section{A tese da complementaridade}

Entre os autores que negam a oposição ou a incompatibilidade entre quantidade e qualidade destacam-se a tese da complementaridade e a tese da unidade. Há nelas um elemento comum: ambas rejeitam a tese da oposição ou dicotomia. Mas termina aí o consenso. Deixando para o item seguinte a tese da unidade, limito-me aqui a algumas consideraçôes sobre a tese da diversidade complementar ou da complementaridade entre os dois tipos de métodos. Santos Filho (2007, p. 45) refere nada menos do que dez pesquisadores que, nos anos de 1979-89, sustentaram a ideia da diversidade complementar. Para o autor, o que caracteriza os seguidores dessa tese é a tendência a “'desepistemologizar' o debate ou ignorar as diferenças paradigmáticas” (ibidem, p. 48). No fundo, se a tese da oposição sustenta a existência de paradigmas claramente definidos e irreconciliáveis entre si, a tese da complementaridade minimiza tais diferenças a ponto de negar o caráter paradigmático dos dois tipos de metodologias.

Mas a coisa não é tão simples assim. Quando o leitor busca esclarecer o significado do termo "complementaridade", defronta-se com diferentes entendimentos a respeito. Richardson et alii (2008, p. 88-89), por exemplo, no brevíssimo tratamento dado ao tema da complementaridade, começam por identificar três "instâncias de integração entre ambos os métodos", a saber, o planejamento da pesquisa, a coleta dos dados e a análise da informação. Ora, o recurso ao termo integração dos métodos sugere que os autores aproximam o conceito de complementaridade ao de unidade dos métodos quantitativos e qualitativos.

Por sua vez, Grawitz, ao tratar da "querela metodológica”, também esclarece o que entende por complementaridade: "A reconciliação do qualitativo, do ideográfico 
e do quantitativo [...] implica a sua complementaridade". Segundo a autora, esta complementaridade "permite utilizar o caso particular em estudo em profundidade, seja para sugerir hipóteses, que a pesquisa quantitativa verificará, seja para dar um sentido aos dados fornecidos por esta última" (Grawitz, 1996, p. 321-322). Mas o que a autora diz na sequência suscita dúvidas sobre o que efetivamente se deva entender por complementaridade. De um lado, sob o título de "Complementaridade do qualitativo e do quantitativo", ela diz predominar entre os pesquisadores a ideia de um "continuum que vai da pesquisa qualitativa sistemática até formas de medida mais rigorosas." (Ibidem, p. 338-339, grifo meu). De outro, ao tratar do método dialético, a autora parece inclinar-se para a tese da unidade dialética:

A dialética é o mais completo, o mais rico e, parece, o mais acabado dentre os métodos voltados para a explicação em sociologia. Ele parte da constatação muito simples das contradiçóes que nos cercam [...] O método dialético parece-nos um método mais completo que os demais, para náo dizer $o$ método, porque ele corresponde às exigências fundamentais da própria noção de método. Ele é antes de tudo uma atitude em face do objeto: empírico e dedutivo, ele comanda por isso mesmo uma certa maneira de coletar os dados concretos. Ele representa em seguida uma tentativa de explicação dos fatos sociais, o que quer dizer que ele está diretamente ligado à noção de totalidade. (Ibidem, p. 399, grifos da autora).

Por fim, Delli Zotti (1996, p.141 e 147) parece não fazer distinção entre unidade e complementaridade. Com efeito, sob o título "4. A estratégia da integração: 'unidade na diversidade", o autor fala em proposta de "integração e/ou convergência" $\mathrm{e}$, mais adiante, em complementaridade e integração das duas abordagens.

\section{Tese da unidade entre quantidade e qualidade: Marx e Gramsci}

Se há diferentes entendimentos do que signifique complementaridade, o mesmo acontece entre aqueles que falam em unidade. Flick (2004), por exemplo, dedica um capítulo inteiro à discussão das relaçóes entre pesquisa qualitativa e quantitativa, relaçôes estas que o autor entende como sendo de unidade, mas não sem recorrer a termos como "integraçáo" e "complementaridade".

$\mathrm{Na}$ linha dos que veem unidade na relação entre quantidade e qualidade, limito-me aqui à tese da unidade na perspectiva da dialética marxista. A respeito, vale salientar a tentativa de Gamboa de construir um entendimento sobre a questão a partir da dialética presente no materialismo histórico, o qual, diz o autor, "em princípio, propóe a síntese como uma das suas categorias basilares" (Gamboa, 2007, p. 101). Segundo o autor: 
As categorias de explicação e compreensão, consideradas em outras abordagens como categorias científicas separadas e independentes, caracterizando tipos diferentes de ciência, na dialética implicam-se mutuamente. As duas se dáo como resultado dos processos de análise, síntese, e do movimento; da passagem do real empírico ao abstrato e deste ao concreto (processos e categorias que se articulam na dinâmica do processo do conhecimento). Na perspectiva dialética, a compreensão e a explicação não são apenas processos intelectualmente conexos, mas sim um só processo, simplesmente referidos a dois níveis diferentes, mas articulados, na construção do objeto. (Ibidem, p. 105).

Nessa concepçáo de unidade, estaria superada a oposição tão frequentemente ressaltada entre as metodologias ditas da explicação, tidas como positivistas (Durkheim, por exemplo) e as metodologias da compreensão (Weber, por exemplo).

No sentido de esclarecer esta perspectiva da unidade dialética, começo recorrendo à obra principal de Marx - O capital, onde, já no primeiro capítulo, o autor explicita com acuidade muito particular que cada coisa útil pode e deve ser considerada sob duplo aspecto: da qualidade e da quantidade. Ele mostra como as mercadorias são, ao mesmo tempo, quantidade e qualidade: "Como valores-de-uso, as mercadorias são, antes de mais nada, de qualidade diferente; como valores-detroca só podem diferir na quantidade, não contendo, portanto, nenhum átomo de valor-de-uso" (Marx, 1998, p. 59). Segundo o exemplo oferecido pelo próprio Marx, linho e casaco são valores de uso qualitativamente diferentes, mas 20 metros de linho podem ser quantitativamente iguais a um casaco, se seus preços se equivalerem. O casaco de Marx ${ }^{5}$, enquanto valor de uso, servia para aquecê-lo, além de conferir-lhe a distinção necessária para entrar no Museu Britânico para suas pesquisas. Para ambos os fins, o casaco era pura qualidade. No entanto, quando empenhado em alguma loja de valores em Londres, o mesmo casaco era pura quantidade (= X libras esterlinas).

Outra ilustração da inseparabilidade que há entre quantidade e qualidade vamos encontrar no estudo do salto qualitativo verificado na passagem das corporaçóes medievais para a produção tipicamente capitalista. "As corporaçóes da Idade Média - diz Marx - procuravam impedir coercitivamente a transformação do mestre artesão em capitalista, limitando a um mínimo o número máximo de trabalhadores que cada mestre podia empregar." (Marx, 1998, p. 355). Para que o possuidor de dinheiro ou de mercadoria pudesse transformar-se realmente em capitalista, era necessário que a soma mínima adiantada para produção ultrapassasse de muito esse limite medieval. E aqui Marx refere Hegel (A lógica), para quem "modificaçôes

5. Sobre isto se poderia ler O casaco de Marx (Stallybrass, 1999). 
quantitativas, além de certo ponto, se transformam em modificaçóes qualitativas" (ibidem, p. 355). Portanto, o próprio Marx reconhece que a fonte dessa sua concepção a respeito da relação entre quantidade e qualidade, assim como da lei do salto qualitativo, é nada menos do que Hegel. Sobre a unidade entre quantidade e qualidade em Hegel, G. Stiehler (1985, p. 191-213) não podia ser mais explícito: "Hegel demonstrou que qualquer existente real constitui uma unidade de determinaçôes quantitativas e de determinaçóes qualitativas".6.

Outra contribuição importante, dentro do marxismo, para a elucidação do tema da relação entre quantidade e qualidade na pesquisa pode ser encontrada nas reflexôes que Gramsci (1966, p. 72) faz a respeito da prática da bruxaria superior a que se costuma dar o nome de ciência. $\mathrm{Na}$ discussão que o autor faz sobre o significado dos termos "ciência" e "científico", lê-se: "O equívoco em torno dos termos 'ciência' e 'científico' nasceu do fato de que eles assumiram seu significado a partir de um grupo determinado de ciências, precisamente das ciências naturais e físicas." O resultado disso foi, segundo o autor, que se acabou chamando de científico todo método que fosse análogo ao método de investigação das ciências naturais, transformadas, assim, em "ciências por excelência, as ciências-fetiche", coisa que simplesmente não existe. Para Gramsci: "Toda pesquisa científica cria para si um método adequado, uma lógica própria, cuja generalidade e universalidade consiste apenas em ser 'conforme ao fim"' (Gramsci, 2001, p. 234-235). Na perspectiva gramsciana, o método não é algo já de antemáo estabelecido, a que as novas ciências se devam adequar e de onde estas possam derivar as aplicaçóes de seu interesse. Ao contrário, cada (nova) ciência - e Gramsci pensa principalmente nas ciências humanas - terá que construir a sua metodologia. Assim, o que pesquisar antecede o como pesquisar.

Gramsci também sustenta a inseparabilidade entre quantidade e qualidade: "Dado que não pode existir quantidade sem qualidade e qualidade sem quantidade (economia sem cultura, atividade prática sem inteligência, e vice-versa), toda contraposição dos dois termos é, racionalmente, um contra-senso.” (Gramsci, 1966, p. 50). E prossegue:

Se o nexo quantidade-qualidade é inseparável, coloca-se a questão: onde é mais útil aplicar a própria força de vontade,

6. G. Wetter, em sua obra Le materialisme dialetique (1962), tratando da relação entre Marx e Hegel no que respeita à unidade (dialética) entre quantidade e qualidade, afirma: "O materialismo dialético reconhece a Hegel o mérito de ter sido o primeiro a formular a lei da passagem da quantidade para a qualidade; infelizmente ele a formulou em termos 'idealistas', neste sentido que quantidade e qualidade aparecem como etapas determinadas no desenvolvimento da idéia absoluta, mas não se reportando a quaisquer objetos materiais". E acrescenta que os fundadores do marxismo corrigiram esse erro, dando à fórmula de Hegel uma interpretação profundamente materialista (Wetter, 1962, p. 34I). 
em desenvolver a quantidade ou a qualidade? Qual dos dois aspectos é mais facilmente controlável? Qual é mais facilmente mensurável? Sobre qual dos dois é possível fazer previsóes, construir planos de trabalho? A resposta parece indubitável: sobre o aspecto quantitativo. Afirmar, portanto, que se quer trabalhar sobre a quantidade, que se quer desenvolver o aspecto "corpóreo" do real, não significa que se pretenda esquecer a "qualidade", mas, ao contrário, que se deseja colocar o problema qualitativo da maneira mais concreta e realista, isto é, deseja-se desenvolver a qualidade pelo único modo no qual tal desenvolvimento é controlável e mensurável. (Gramsci, 1966, p. 50).

Argumentando contra a pretensão de separar as duas dimensóes do real, o autor diz que "sustentar a 'qualidade' contra a 'quantidade' significa, precisamente, apenas isto: manter intactas determinadas condiçôes de vida social, nas quais alguns são pura quantidade, outros pura qualidade." E exemplifica, em tom irônico: "E como é agradável manter representantes laureados da qualidade, da beleza, do pensamento etc.! Náo existe senhora do 'grande mundo' que náo acredite cumprir esta função de conservar sobre a terra a qualidade e a beleza!" (Gramsci, 1966, p. 50-51). Em outra passagem, o autor sustenta que, "na filosofia da práxis, a qualidade está sempre ligada à quantidade", para, na sequência, dirigir dura crítica tanto ao idealismo, que "hipostasia este 'algo mais', a qualidade, fazendo dele um ente em si, o 'espírito", quanto ao materialismo vulgar, que “diviniza' uma matéria hipostasiada” (Gramsci, 2001, p. 164).

Se recorri a Marx e a Gramsci, é porque entendo que esses autores oferecem elementos fundamentais para poder avançar na discussão da relação entre quantidade e qualidade na pesquisa nas ciências sociais em geral e na educação em particular. E eles fazem isso pelo caminho que leva o nome de dialética. Mas a dialética posta "de cabeça para cima", não a dialética "de cabeça para baixo", como no idealismo hegeliano (Marx, 1998, p. 29). Pode parecer extemporâneo lembrar Marx, Gramsci, a dialética, enfim, o marxismo, e fazer isso justamente quando, depois de sua ascensão arrasadora a partir do início dos anos 1970, o neoliberalismo conseguiu impor-se como pensamento único ou, como observa Derrida em Espectros de Marx (1994, p. 82), como "um novo evangelho, o mais barulhento, o mais midiático, o mais 'successful' acerca da morte do marxismo como fim da história". É que, por mais que o neoliberalismo tenha proclamado e continue proclamando: "Marx está morto [...]; viva o capitalismo, viva o mercado, sobreviva o liberalismo econômico e político!", talvez seja oportuno não esquecer o alerta do já citado Derrida, quando diz que, por mais que se queira expulsar, excluir, exorcizar um espectro, é importante lembrar que "um fantasma não morre nunca, está sempre por vir ou por retornar” (ibidem, p. 76 e 136-137)! 


\section{"Quem quer a verdade sobre o mundo social?"}

A pergunta é de Pierre Bourdieu. Em entrevista concedida a J. Heilbron e B. Maso, em 1983, em Amsterdam, perguntado sobre as funçôes sociais da Sociologia e da demanda "externa", Bourdieu respondeu de forma inequívoca com uma pergunta indireta: "Primeiro, é preciso perguntar se existe realmente uma demanda por um discurso científico em ciências sociais". E acrescentou: "Quem quer a verdade sobre o mundo social?” (Bourdieu, 2004, p. 67). Obviamente, a expressão "mundo social" é empregada em sentido abrangente, incluindo também o mundo da educação. A questáo levantada por Bourdieu aplica-se, assim como a todos os objetos de pesquisa, também às respectivas metodologias. Se não, vejamos.

Em relação às estatísticas e aos estatísticos, Annie Fouquet (1995, p. 163-164) pergunta: "Mas onde trabalha este estatístico, este magistrado da cifra? Que instituição o patrocina? Ele fica fora do debate? Ou é parte integrante dele?” E adverte: "A cifra que o estatístico do ministério produz corre o risco de desmentir a política do ministro que paga seus serviços".

No campo da pesquisa qualitativa enfrenta-se desafio semelhante. É Érico Veríssimo quem esclarece esse aspecto no romance Incidente em Antares. Um dos membros da equipe de pesquisadores, que se entregava a uma pesquisa sobre hábitos sexuais da população antarense, tema talhado para recurso a técnicas qualitativas, recebe o seguinte alerta do professor Martin Francisco, coordenador da pesquisa: "Excelente! Mas não podemos usar esse material no nosso estudo. Causaríamos um escândalo dos diabos" (Veríssimo, 1973, p. 131). Mesmo com toda essa cautela, "como era de se esperar, os pró-homens de Antares detestaram o livro, que um mês mais tarde foi discutido a portas fechadas numa reunião convocada pelo prefeito especialmente para esse fim." (Ibidem, p. 136).

Em relação a isso, retorno a Bourdieu, na entrevista já citada (2004, p. 50), onde ele diz que "boa parte dos trabalhos de 'teoria' e 'metodologia' são apenas ideologias justificadoras de uma forma particular de competência científica”. Penso que, em vez de nos inquirirmos sobre qual a competência metodológica de maior valor, talvez seja mais proveitoso perguntarmo-nos se e como diferentes competências metodológicas poderão articular-se no estudo de um determinado problema social ou educacional. De qualquer forma, é na construção do objeto ou do problema de pesquisa que se poderá definir o método ou a combinação de métodos e técnicas a empregar na investigação.

E, para finalizar, reafirmo o entendimento de que a dialética marxista (a dialética posta de "de cabeça para cima", ou com os pés no chão, na perspectiva do materialismo histórico, com destaque para Marx e Gramsci) se constitui em caminho promissor para poder avançar na discussão da relação entre quantidade e qualidade na pesquisa, tanto nas ciências sociais em geral, quanto na educação em particular. 
Nessa perspectiva dialética, simplesmente não há quantidade sem qualidade, nem qualidade sem quantidade; a unidade entre essas duas dimensôes do real está em sua inseparabilidade ou exigência recíproca, não em qualquer identidade imaginária entre ambas. Essa perspectiva dialética permite, antes de tudo, afastar duas concepçóes opostas e igualmente vulneráveis: de um lado, a daqueles(as) que veem incompatibilidade, dicotomia ou oposição excludente entre métodos quantitativos e métodos qualitativos; de outro, a daqueles(as) que veem unidade entre os dois tipos de métodos - uma unidade construída não sobre a diferença que os distingue, mas sobre uma identidade imaginária que desfigura uns e outros, na medida em que ignora ou apaga as diferenças. Permite ainda afastar a tese de um continuum entre quantidade e qualidade, que acaba por restabelecer, nas posiçóes extremas, a dicotomia quantidade-qualidade e, consequentemente, a exclusão mútua entre essas duas dimensóes. Por fim, permite afastar a tese sedutora da complementaridade, a qual, ao mesmo tempo que obriga a enfrentar a capciosa questáo sobre quais métodos complementam quais outros, implica uma hierarquização problemática entre os dois tipos de métodos.

\section{Referências bibliográficas}

ANDRÉ, M. E. D. A. de. Etnografia da prática escolar. 7. ed. Campinas, SP: Papirus, 2002.

BESSON, J-L. (Org.). A ilusão das estatísticas. São Paulo: Unesp, 1995a.

BESSON, J-L. As estatísticas: verdadeiras ou falsas? In: BESSON, J-L. (Org.). A ilusão das estatísticas. São Paulo: Unesp, 1995b. p. 25-67.

BESSON, J-L. Nem tanto excesso de honra, nem tanta indignidade. In: BESSON, J-L. (Org.). A ilusão das estatísticas. São Paulo: Unesp, 1995c. p. 257-261.

BOURDIEU, P. Coisas ditas. São Paulo: Brasiliense, 2004.

BURGESS, R. G. A pesquisa de terreno: uma introdução. Oeiras: Celta, 1997.

COMTE, M. Três milhōes de desempregados. In: BESSON, J-L. (Org.). A ilusão das estatísticas. São Paulo: Unesp, 1995. p. 95-111.

CONDORCET, J-A. N. de C., Marquês de. Esboço de um quadro histórico dos progressos do espirito humano. Campinas: Unicamp, 1993.

DELLI ZOTTI, G. Quale quantità e quanta qualità nella ricerca sociale: tra integrazione e convergenza. In: CIPOLLA, C.; DE LILLO, A. (Org.). Il sociologo e le sirene. La sfida dei metodi qualitativi. Milano: Angeli, 1996. p. 136-166.

DERRIDA, J. Espectros de Marx. o estado da dívida, o trabalho do luto e a nova Internacional. Rio de Janeiro: Relume-Dumará, 1994.

DURKHEIM, É. As regras do método sociológico. Tradução de Maria Isaura Pereira de Queiroz. 6. ed. São Paulo: Companhia Editora Nacional, 1971. 
FARIA FILHO, L. M. de; NEVES, L. S.; CALDEIRA, S. M. A estatística educacional e a instrução pública no Brasil: aproximaçôes. In: CANDEIAS, A. (Coord.). Modernidade, educação e estatística na Ibero-América dos séculos XIX e XX: estudos sobre Portugal, Brasil e Galiza. Lisboa: Educa, 2005. p. 219-238.

FLICK, U. Uma introdução à pesquisa qualitativa. Tradução de Sandra Netz. Porto Alegre: Bookmann, 2004.

FOUQUET, A. Visita a uma empresa. In: BESSON, J-L. (Org.). A ilusão das estatísticas. Sáo Paulo: Unesp, 1995. p. 163-166.

GAMBOA, S. S. Quantidade-qualidade: para além de um dualismo técnico e de uma dicotomia espistemológica. In: SANTOS FILHO, J. C. dos; GAMBOA, S. S. Pesquisa educacional: quantidade-qualidade. 6. ed. Sáo Paulo: Cortez, 2007. p. 84-110.

GATTI, B. A. Estudos quantitativos em educação. Educação e Pesquisa, São Paulo, v. 30, n. 1, p. 11-30, jan./abr. 2004.

GIL, N. de L. A dimensão da educação nacional: um estudo sócio-histórico sobre as estatísticas oficiais da escola brasileira. Tese (Doutorado em Educação) - Faculdade de Educação da Universidade de São Paulo, São Paulo, 2007. 409 p.

GOODE, W. J.; HATT, P. K. Métodos em pesquisa social. 3. ed. São Paulo: Companhia Editora Nacional, 1969.

GRAMSCI, A. Concepção dialética da história. Rio de Janeiro: Civilização Brasileira, 1966.

GRAMSCI, A. Cadernos do cárcere. Ed. Carlos Nelson Coutinho. Rio de Janeiro: Civilizaçáo Brasileira, 2001. v. 1.

GRAWITZ, M. Méthodes des sciences sociales. 10. ed. Paris: Dalloz, 1996.

LESSARD-HÉBERT, M.; GOYETTE, G.; BOUTIN, G. Investigação qualitativa: fundamentos e práticas. Lisboa: Instituto Piaget, 1994.

LÖWY, M. Ideologias e ciência social. Elementos para uma análise marxista. São Paulo: Cortez, 1985.

LÖWY, M. As aventuras de Karl Marx contra o Barão de Minchausen. Marxismo e positivismo na sociologia do conhecimento. 2. ed. São Paulo: Busca Vida, 1988.

MARX, Karl. O capital. 16. ed. Rio de Janeiro: Civilizaçáo Brasileira, 1998. 1. 1, v. 1.

PHILLIPS, B. S. Pesquisa social: estratégias e táticas. Rio de Janeiro: Agir, 1974. p. 129.

RICHARDSON, R. J. et alii. Pesquisa social: métodos e técnicas. 3. ed. rev. e aum. 8. reimpr. São Paulo: Atlas, 2008.

SANTOS FILHO, J. C. Pesquisa quantitativa versus pesquisa qualitativa: o desafio paradigmático. In: SANTOS FILHO, J. C. dos; GAMBOA, S. S. Pesquisa educacional: quantidade-qualidade. 6. ed. São Paulo: Cortez, 2007. p. 13-59

SANTOS FILHO, J. C. dos; GAMBOA, S. S. Pesquisa educacional: quantidade-qualidade. 6. ed. Sáo Paulo: Cortez, 2007. 
STALLYBRASS, P. O casaco de Marx: roupas, memória, dor. Tradução de Tomaz Tadeu da Silva. Belo Horizonte: Autêntica, 1999.

STIEHLER, G. A filosofia de Hegel, uma das origens teóricas da concepção do mundo de Marx e Engels. In: VILHENA, V. de M. Marx e Hegel (Marx e o “caso” Hegel). Lisboa: Livros Horizonte, 1985. p. 191-213.

VERÍSSIMO, É. Incidente em Antares. 1. ed., 9. impr. Porto Alegre: Globo, 1973.

WETTER, G. Le materialisme dialectique. Traduit de l'allemand par F. Ollivier. Bruges: Desclée de Brouwer, 1962.

Recebido em 02 de março de 2011 e aprovado em 05 de agosto de 2011. 